\title{
How vibrations affect steel-to-concrete adherence
}

\author{
Anna Wojtowicz ${ }^{*}$, Andrzej Ubysz and Jarosław Michałek \\ Wroclaw University of Science and Technology, Faculty of Civil Engineering, \\ 27 Wybrzeże Wyspiańskiego St. 50-370 Wrocław, Poland
}

\begin{abstract}
In view of location and tight work schedule of civil projects, more and more frequently the various kinds of work overlap each other in space and time. Hence, their interactions need to be anticipated. An example of such works are pile driving which generate vibrations, which begs a question whether and to what extent they affect proper operation of other structures being constructed at the same time, e.g. reinforced concrete elements. This paper deals with the problem of steel-to-concrete adherence in reinforced concrete elements by providing mechanism of adherence destruction, methods use to determine adherence stresses and outlining analytical and numerical methods. Examinations on how vibrations affect fresh concrete mix are provided in the latter part of the paper. At the end, further direction for development is discussed.
\end{abstract}

\section{Introduction}

Short terms of project completion envisaged at planning stage directly force tough deadline for construction works. This makes it necessary to carry out different construction works simultaneously. Due to condensation of works, in time and spatial domains, close coordination of works is required, especially to minimize adverse effects of their interaction. Basic restrictions and guidelines need to be known to make proper evaluation of harmfulness of factors generated by neighbouring works. However, such analyses are not easy to run as there are numerous variants possible. Each project has specific determinants and trying to make any systematisation leads to loss of their peculiar nature. Hence, contraindications to carrying out works close to another-type ones can be of just general nature. Frequently, when we want to stay on safe side, too large restrictions are imposed which result in extended time and higher cost of project completion.

The works generating vibrations are an example of works which could affect other ones in close vicinity. Exemplary cases when geotechnical works affect surroundings of construction site are shown in references [1-4]. Harmful impacts, for instance, include pile driving [5], dynamic substrate compaction and blasting works [6]. Vibrations may be also due to simultaneous demolition works run with heavy machinery, or - depending on site location - due to vehicle traffic close to working area. More and more frequently the contractors and engineering staffs are asking: do the vibrations affect, and in which way,

\footnotetext{
* Corresponding author: anna.wojtowicz@pwr.edu.pl
} 
the neighbouring works, and especially the process of concreting elements and setting of concrete. As the most of geotechnical technologies make it possible to reduce the energy of single impact or vibration frequency, dynamic impact of the works can be to some extent controlled. Examples of proper calibration of geotechnical works are given in works $[7,8]$.

The substance of reinforced concrete structures is proper cooperation of two composite materials: steel and concrete. Thus, the effect of vibrations should not be examined for constituent materials, but first and foremost for the adhesion between them. Examinations which verify mechanical properties of hardened concrete, which subjected to dynamic influences during early stage of setting, are available in literature. But just few publications deals with adhesion stress change. It is necessary to have knowledge of this problem to allow for precise determination of strain distribution in steel and concrete, which as a consequence enables to imitate scratches in reinforced concrete structure.

This paper discusses the question of steel adhesion to concrete in reinforced concrete element by introducing the mechanism of destruction and the methods used to determine adhesion stresses. Also, the analytical and numerical methods are outlined. Later, the paper presents examinations carried by now on how vibrations affect green concrete. At the end, further direction of development is discussed.

\section{Adhesion of steel to concrete in reinforced concrete elements}

\subsection{Factors affecting adhesion stresses}

Adhesion consists in mutual transfer of forces between reinforcing bars and concrete. The mechanism of this cooperation is the essence of reinforced concrete. Adhesion stresses depend on many factors. Paper [11] distinguishes the following factors: adhesion; concrete pressure against bar resulting from shrinkage of drying concrete; shearing force of the joint between bar ribs and concrete; resistance to slip caused by friction depending on tension bar stresses; compression and tensile strength of concrete; mechanical termination of bars by means of loops or hooks along proper anchorage length; diameter and shape of bar and arrangement of bars. Quantitative share of these factors can hardly be determined. Table 1 summarizes the factors tested experimentally.

Table 1. Bibliography review on experimentally analyzed factors affecting adherence acc. to [11]

\begin{tabular}{|c|c|c|}
\hline \multicolumn{3}{|c|}{ The influence of the following as investigated in bibliography } \\
\hline $\begin{array}{c}\text { Geometry and arrangement } \\
\text { of reinforcement }\end{array}$ & $\begin{array}{l}\text { Bar surface type and } \\
\text { environmental conditions }\end{array}$ & $\begin{array}{c}\text { State of stresses } \\
\text { in surrounding concrete }\end{array}$ \\
\hline $\begin{array}{l}\text { Arrangement of bars in formwork } \\
\text { and direction of concreting }\end{array}$ & $\begin{array}{l}\text { Influence of low and high } \\
\text { temperatures }\end{array}$ & $\begin{array}{c}\text { Tensile stress } \\
\text { perpendicular to lap joint }\end{array}$ \\
\hline Longitudinal strain of bars & $\begin{array}{l}\text { Bar surface: rusty, galvanized, } \\
\text { greased or zinc coated }\end{array}$ & \multirow{3}{*}{$\begin{array}{c}\text { Transverse pressure and } \\
\text { tensile stress along } \\
\text { anchorage length }\end{array}$} \\
\hline $\begin{array}{l}\text { Strain of tensioned bars } \\
\text { considering Poisson's ratio }\end{array}$ & \multirow{2}{*}{$\begin{array}{l}\text { Reinforcement corrosion caused } \\
\text { by migration of chlorides, } \\
\text { sulfates, } \mathrm{CO}_{2} \text { and oxygen }\end{array}$} & \\
\hline Relative surface area of ribs & & \\
\hline Nature of load & Boundary conditions & Anchorage length \\
\hline Fatigue & Concrete cover & \\
\hline Cyclic load & $\begin{array}{l}\text { Restrictions of transverse } \\
\text { concrete strains next to bar }\end{array}$ & \\
\hline
\end{tabular}


This review shows the complexity of issues. It also reveals that dynamic actions, i.e. vibrations, independently of their source, during element hardening were not analyzed, both theoretically and in connection with reduced load bearing of contact with respect of that designed.

\subsection{Adherence destruction mechanism}

The problem of adherence can be considered at various levels of detail (Figure 1). Description of adherence stress pattern for bar rib is the easiest to describe and also is quite carefully examined. A successive level, including more variables, e.g. anchorage length, diameter or shape, refers to reinforcement bar. For this case, there are also numerous descriptions of adherence mechanism in bibliography. The least identification is for the level of constructional element due to multitude of factors affecting final value of adherence stresses, and there is no universal model describing the phenomenon.

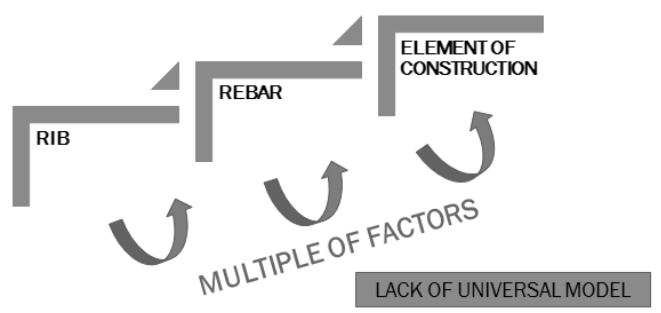

Fig. 1. Bond stress -levels of detail.

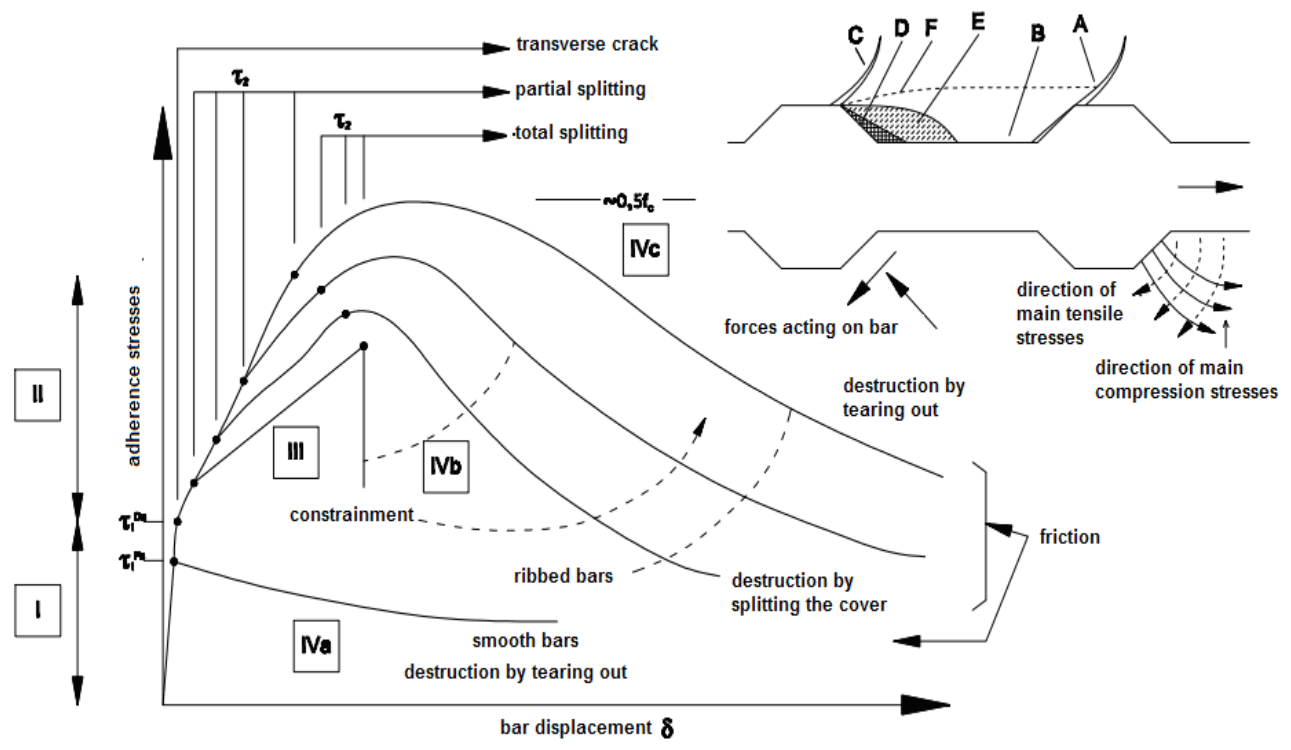

Fig. 2. Adherence stress pattern depending on bar displacement in relation to concrete [10] acc. to [9] and mechanism of adherence operation.

Four stages of adherence stress distribution [9] can be distinguished depending on displacement of bar in relation to concrete (Fig. 2). During the first stage, when element remains unscratched, strains of concrete and steel are the same. This is caused by adhesion intermolecular forces. Here is so called the primary adhesion. Smooth bar reaches here the maximum adherence stresses and it comes to destruction (stage IVa). 
In case of ribbed bars, the end of this stage is a shift of reinforcement with respect of concrete and appearance of the first scratch (scratches A and B). Stage II involves irreversible damages in element. Bar displacement keeps getting bigger and bigger, successive scratches come out (C). The first crushing of concrete (D, E) - stage III - causes increase of stress in steel and bar contraction. Destruction of concrete before rib face is preceded by longitudinal scratches, parallel to reinforcement $(\mathrm{F})$. The maximum value of adherence stress of ribbed bar is achieved. Destruction of element with ribbed bar may occur in two ways: by splitting the concrete cover (stage IVb) or tearing the reinforcement bar out (stage IVc). In the first case, through actions which restrict strains, the destruction is preceded by longitudinal scratches parallel to the bar axis. In the second case, it comes about to concrete truncation close to rib face.

\subsection{Experimental methods used for adherence testing}

The ,pull-out" method is the basic one used to examine adherence. Assumption is made that changes of strains along bar are of linear pattern (for anchorage section from three to five bar diameters, the adherence strain distribution is constant). Thanks to that fact, the value of adherence stress can be calculated by dividing the pulling out force $\mathrm{F}$ by the contact area between bar and concrete. This method is popular due to simple examination measurement of force and displacement; hence it can be used for large amount of samples, which can subject to tests for various influencing factors. Unfortunately, it does not imitate true operation of a structure. In examination, concrete is compressed and the bar is stretched. But during bending, concrete surrounding the bar subject also to stretching.

Additionally, a short section of adherence causes inflated values of secondary adherence with respect to natural scale (it is not possible for internal scratches to arise). The destruction mechanism during testing consists in tearing out the bar from concrete cube. In real elements, where cover is much less, it is more probable that the concrete cover would be split up.

\subsection{Analytical methods and numerical modelling}

There are many analytical methods for determining adherence stresses. The paper [9] makes a review of formulae enabling to find the values of this influence. Both the standards [10] and numerous publications point out, in each case, the dependence of concrete strength features - mainly the tensile strength (in some formulae square root of compression strength is used, which approximately equals to the tensile strength). In some relationships, the adherence stresses are also dependent on geometrical parameters - reinforcement diameter, cover and anchorage length. Unfortunately, there are no mathematical models which include other factors, which are much harder to define, like e.g. vibrations.

Numerical modelling enables to get much more information out of element under testing. It is an alternative for experimental studies, provided a proper model is worked out. Troubles and difficulties manifest themselves in the way of defining behaviour of material and connection at steel-to-concrete contact. Often enough some indirect studies are necessary, e.g. to introduce the stress-strain relationship. While for single-axis compression the case seems not to be awkward, but for stretching it is.

Large discrepancy of results and problems with testing procedure cause that indirect methods are used, e.g. testing for tensile strength at splitting or bending. For the results found with numerical modelling represent real operation of elements, each parameter should be well defined and described. 


\section{Impact of vibrations on properties of hardened concrete}

\subsection{Impact outline}

Impact of dynamic loads on green concrete may be considered in two phases, before and after beginning of setting. During the phase of laying down and compacting concrete mix one should expect an advantageous effects of vibrations improving compacting, spreading inside formwork and "wrapping" reinforcement bars. Research of Marx [12] proved that vibrations could improve adherence as much as even up to $10 \%$. Regrettably, also negative effect may appear as segregation of components - like for excessive vibrating. Harsh and Darwin [13] demonstrated in their research that this effect may outweigh the benefits from better compaction (reduction of strength by $5 \%$ as compared with increase of strength by $4 \%$ ). Following start of setting and concrete hardening, vibrations accompanying concrete setting have negative impact only. This thesis can be confirmed by FIB guidelines of 1991 [14], which recognized the vibrations below $20 \mathrm{~mm} / \mathrm{s}$ as negligible, while those over 100 $\mathrm{mm} / \mathrm{s}$ were admitted, provided the concrete has already reached the strength of $6 \mathrm{MPa}$.

The time between 3 and 14 hour of maturing was considered to be of critical importance. Similar conclusions can be also found in paper of Ansell and Silfwerbrand [15]. Table 2 shows admissible maximum speeds during various phases of regular concrete maturation as they determined.

Table 2. Limitations of maximum vibrations velocity (ppv) accompanying concrete setting [15]

\begin{tabular}{|c|c|c|}
\hline & Age of concrete & Max ppv (mm/s) \\
\hline Fresh concrete mix & $0-3$ hours & 100 \\
\hline Young concrete & $3-12$ hours & 35 \\
\hline Early concrete & $12-24$ hours & 50 \\
\hline Almost hardened & $1-2$ days & 100 \\
\cline { 2 - 3 } concrete & $2-7$ days & 175 \\
\hline \multirow{2}{*}{ Hardened concrete } & $7-10$ days & 225 \\
\cline { 2 - 3 } & $>10$ days & 300 \\
\hline
\end{tabular}

\subsection{Review of most important publications}

As there are significant restrictions of time and place for concreting a reinforced concrete elements while vibrations are involved (or when they are entirely absent), publications may be found which try to examine the effect of vibration of fresh concrete mix on strength properties of hardened element and to define real threshold values. There are numerous (previously mentioned) papers concerning the influence of geotechnical works (in-situ). Other contributions focus on laboratory testing of concrete samples exposed to vibrations.

\subsubsection{Acceptable vibrations on green concrete}

Freyne and Watkins in [16] essayed to prove that boundary conditions for deep foundation formation were too restrictive, which resulted in extended schedule and higher costs of building projects. The research model constitutes of cylindrical concrete samples which subjected, at various stages of setting, to vibrations of different speeds. A constant composition of concrete matrix (cement I/II - 360kg/m3, w/c - 0.44), concrete class $(\mathrm{C} 30 / 35)$, consistence $(150 \mathrm{~mm})$ and sample geometry - these parameters were adapted to actual deep foundations. The variables were: duration of vibrations, speed of vibrations and time when they started, and also aggregate used. 
Results, summarized in Tables 3 and 4, represent the compressive strength measured for vibrated cylinders as compared to control cylinders, and are expressed in percentages (like for concrete resistance understood as scratching). Positive values mean that vibrations improve compressive strength, while negative ones, marked with brackets, mean adverse effect of vibrations.

Table 3. Concrete compressive strength results relative to control cylinders according to [16].

\begin{tabular}{|c|c|c|c|c|c|c|c|}
\hline \multirow{2}{*}{$\begin{array}{c}\text { Vibration } \\
\text { Duration }\end{array}$} & \multirow{2}{*}{$\begin{array}{l}\text { Vibration } \\
\text { Intensity }\end{array}$} & \multicolumn{6}{|c|}{ Compressive strength results with } \\
\cline { 3 - 8 } & & 2 hours & 4 hours & 6 hours & 2 hours & 4 hours & 6 hours \\
\hline \multirow{2}{*}{$10 \mathrm{~min}$} & $1.0 \mathrm{in} / \mathrm{s}$ & $4.7 \%$ & $2.6 \%$ & $(1.9 \%)$ & $0.0 \%$ & $2.7 \%$ & $2.2 \%$ \\
\hline \multirow{3}{*}{$20 \mathrm{~min}$} & $0.5 \mathrm{in} / \mathrm{s}$ & & $3.8 \%$ & & & $1.9 \%$ & \\
\cline { 2 - 9 } & $1.0 \mathrm{in} / \mathrm{s}$ & $(5.8 \%) \#$ & $0.9 \%$ & $(0.7 \%)$ & $(1.5 \%) \#$ & $4.9 \%$ & $(1.1 \%)$ \\
\cline { 2 - 9 } & $1.5 \mathrm{in} / \mathrm{s}$ & & $(0.7 \%)$ & & & $3.1 \% \#$ & \\
\cline { 2 - 9 } & $2.0 \mathrm{in} . \mathrm{s}$ & & $3.6 \%$ & & & $0.0 \%$ & \\
\hline $30 \mathrm{~min}$ & $1.0 \mathrm{in} / \mathrm{s}$ & $0.0 \%$ & $3.9 \%$ & $1.7 \%$ & $(2.5 \%)$ & $(2.0) \%$ & $(3.8 \%)$ \\
\hline
\end{tabular}

Table 4. Concrete resistivity results relative to control cylinders according to [16].

\begin{tabular}{|c|c|c|c|c|c|c|c|}
\hline \multirow{2}{*}{$\begin{array}{c}\text { Vibration } \\
\text { Duration }\end{array}$} & \multirow{2}{*}{$\begin{array}{l}\text { Vibration } \\
\text { Intensity }\end{array}$} & \multicolumn{5}{|c|}{ Time after Batch at Start of Vibrations } \\
\cline { 2 - 8 } & & 2 hours & 4 hours & 6 hours & 2 hours & 4 hours & 6 hours \\
\hline \multirow{2}{*}{$10 \mathrm{~min}$} & $1.0 \mathrm{in} / \mathrm{s}$ & $(7.5 \%) \#$ & $(8.1 \%)$ & $5.0 \%$ & $14.6 \%$ & $8.7 \%$ & $5.8 \%$ \\
\hline \multirow{3}{*}{$20 \mathrm{~min}$} & $0.5 \mathrm{in} / \mathrm{s}$ & & $1.4 \%$ & & & $3.0 \%$ & \\
\cline { 2 - 9 } & $1.0 \mathrm{in} / \mathrm{s}$ & $4.7 \%$ & $(3.0 \%)$ & $(4.9 \%) \#$ & $(1.3 \%) \#$ & $10.8 \% \#$ & $15.3 \%$ \\
\cline { 2 - 9 } & $1.5 \mathrm{in} / \mathrm{s}$ & & $(1.7 \%)$ & & & $(0.7 \%)$ & \\
\cline { 2 - 9 } & $2.0 \mathrm{in} . \mathrm{s}$ & & $(7.9 \%) \#$ & & & $(3.8 \%)$ & \\
\hline $30 \mathrm{~min}$ & $1.0 \mathrm{in} / \mathrm{s}$ & $2.3 \%$ & $(9.7 \%)$ & $4.3 \%$ & $(1.9 \%)$ & $(2.7 \%)$ & $(2.6 \%)$ \\
\hline
\end{tabular}

Basing on the research carried out, one can notice that there is no clearly visible trend. A change in strength with respect to sample not subjected to vibrations is not higher than $5 \%$ (for resistance this threshold is higher $-15 \%$ ). Also no significant differences were noticed for the types of aggregate used. It should however be noted that there are significantly different scales of phenomena - cylindrical samples and deep foundations; in the latter case the vibrations could be differently absorbed. Additionally, the tests did not take into account the influence of concrete mix consistence on the final results.

\subsubsection{Effect of vibration time on strength of ordinary and high performance concrete}

Arslan et al. [17] examined effects of vibrations from concrete vibration on strength of ordinary and high performance concrete. The purpose of testing was to verify how the vibration time affects concrete parameters and to determine the optimum vibration time. Constant geometry of samples and composition of concrete matrix (CEM II for ordinary and CEM I for high performance concrete) was assumed. Duration of vibrations, concrete class and w/c ratio were taken as variables. The relationship between compressive strength and duration of vibrations is shown in diagrams, Table 5. 
Table 5. Relationship between compressive strength and duration of vibrations acc. to [17].

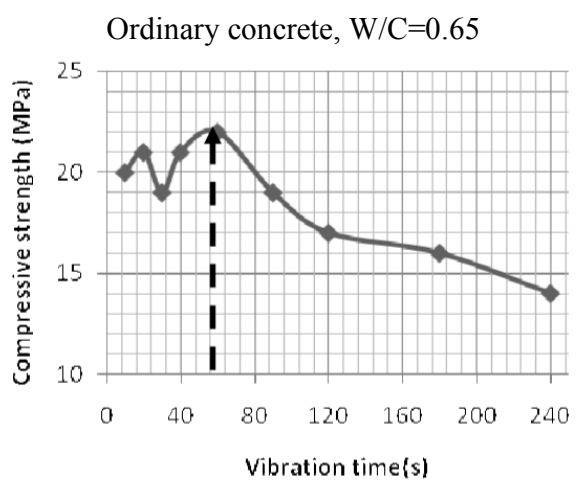

High performance concrete, $\mathrm{W} / \mathrm{C}=0.40$

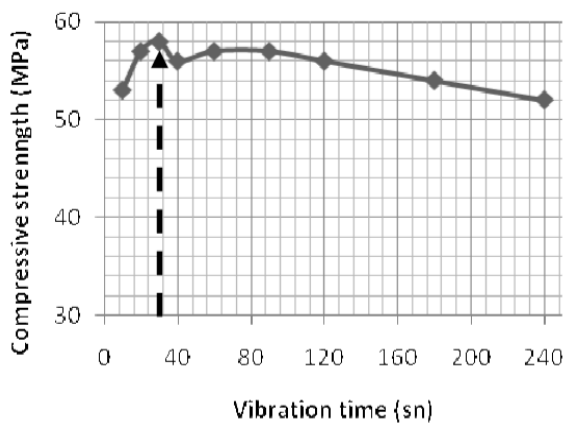

Ordinary concrete $\mathrm{W} / \mathrm{C}=0.55$

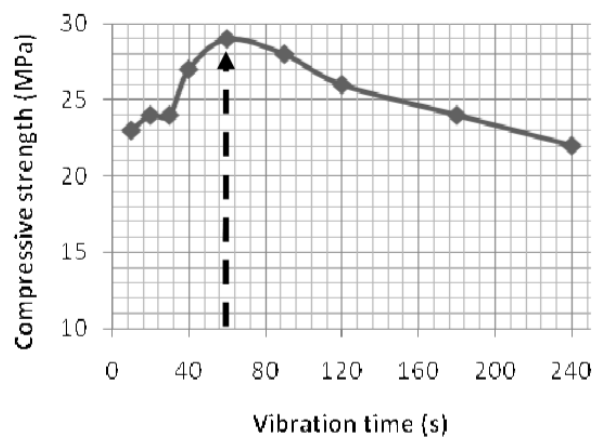

High performance concrete, $\mathrm{W} / \mathrm{C}=0.35$

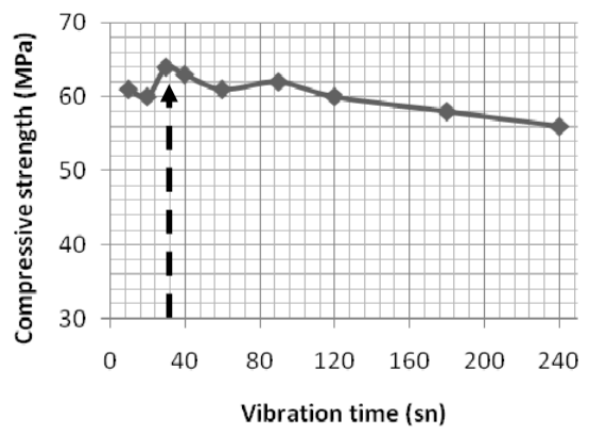

The following conclusions can be drawn from these results:

1. When $\mathrm{W} / \mathrm{C}$ ratio increases, extended time of vibration adversely affects concrete strength. Liquefied concrete mix promotes segregation of components at extended time.

2. The optimum vibration time for ordinary concrete is determined as $60 \mathrm{~s}$. Longer or shorter vibrations reduce compressive strength. Depending on W/C ratio, the strength is reduced even by $36 \%$ at $240 \mathrm{~s}$ with respect to that for $60 \mathrm{~s}$ of vibrations.

3. The optimum vibration time for high performance concrete is shorter $-30 \mathrm{~s}$. In case when vibrations last $240 \mathrm{~s}$, the strength is reduced by $11 \%$ with respect that for $30 \mathrm{~s}$ of vibration, depending on the $\mathrm{W} / \mathrm{C}$ ratio. The reason of that may consist in using high class cement and higher dose of plasticizers and admixtures.

\section{Effect of vibrations on adherence}

Literature review for the subject proves that the problem of how vibrations affect mechanical properties of hardened reinforced concrete element is discernible. While a change of concrete strength properties is tentatively identified, few publications deal with changes of adherence stresses. From examinations of Freyne and Watkins [16] mentioned above one can conclude about a drop of adherence stresses (deterioration of resistance understood as scratch). Harsh and Darwin in their publication [13], dealing with repairs of reinforced concrete bridges during vibrations from vehicle traffic, examined a change in compressive strength and adherence stresses. As variable factors they assumed cover, bar diameter and mix consistence - slump test value. It was stated that effect of vibrations is higher for less cover. However, attention should be drawn to the consistence of concrete mix. The more liquefied is the mix (larger slump), the higher is bond strain drop due vibrations. 


\section{Conclusions}

Adherence of steel to concrete is the fundamental issue in mechanics of reinforced concrete. The factors affecting the adherence stress values are difficult to quantify. There is no synthetic model describing the phenomenon and problem deserves an enhanced study.

\section{References}

1. W. Brzakala, A. Herbut, J. Rybak, Recommendations for ground vibrations survey in course of geotechnical works. $14^{\text {th }}$ Int. Multidisciplinary Scientific GeoConference SGEM 2014, 2 (1), 747-754 (2014)

2. A. Herbut, J. Rybak, Guidelines and recommendations for vibration control in the case of rapid impulse compaction, Advances and trends in engineering sciences and technologies II, CRC Press, Taylor \& Francis Group, 761-766, (2017)

3. F. Oliveira, I. Fernandes, Influence of geotechnical works on neighboring structures, $17^{\text {th }}$ Int. Multidisciplinary Scientific GeoConference SGEM, 17 (12), 993-1002 (2017)

4. M. Wyjadłowski, Stud. Geotech. Mech., 39 (4), 121-129 (2017)

5. W. Brząkała, M. Baca, The measurement and control of building vibrations in course of sheet pile wall and Franki pile driving, $17^{\text {th }}$ Int. Multidisciplinary Scientific GeoConference SGEM, 17 (12), 929-936 (2017)

6. D. Papan, V. Valašková and M. Drusa, Numerical and Experimental Case Study of Blasting Works Effect, IOP Conference Series: Earth and Environmental Science, 44 (5), 052052 (2016)

7. J. Rybak, J. Pieczynska-Kozlowska, Vibration monitoring as a tool for a calibration of geotechnical technologies, $14^{\text {th }}$ Int. Multidisciplinary Scientific GeoConference SGEM, Hydrogeology, engineering geology and geotechnics, 2 (1), 1043-1050 (2014)

8. J. Rybak, A.G. Tamrazyan, Calibration of rapid impulse compaction on the basis of vibration velocity control, $16^{\text {th }}$ Int. Multidisciplinary Scientific GeoConference SGEM, 1, 715-722 (2016)

9. M. Kijana, Przegląd Budowlany, 6, 38-42 (2015)

10. Model Code, Final Draft - Volume 1. FIB Biuletin 65 (2012)

11. P. Smarzewski, A. Stolarski, Biuletyn WAT, 1, 147-166 (2007)

12. S. Marx, Concrete production under traffic vibration. The $11^{\text {th }}$ Annual International fib Symposium ,, Concrete : $21^{\text {st }}$ Century Superhero-Building a sustainable future”. June 2224, London, Session D-7 Structures \&Construction (CD), 1-8 (2009)

13. S. Harsh, D. Darwin, Traffic Inducted Vibrations and Bridge Deck Repairs. Concrete International, 8 (5), 36-42 (1986)

14. FIP Guide to good practice : Repair and strengthening of concrete structures. Thomas Telford Services Ltd., London, (1991)

15. A. Ansell, J. Silfwerbrand, The vibration resistance of young and early age concrete. Structural concrete, 4 (3), 125-134, (2003)

16. S.F. Freyne, M.L. Watkins, Acceptable vibrations on green concrete final report. FHWA Technical Report Documentation, State Study 252, (2013)

17. M.E. Arslan, E. Yozgat, S. Pul, M. Husem, Effects of vibration time on strength of ordinary and high performance concrete, $4^{\text {th }}$ WSEAS international conference on Energy and development - environment - biomedicine, (2011) 